\title{
Potential COVID-19 Effects on Reproductive Systems and Fertility; ART Guidelines and Considerations: A Review
}

\author{
Wing Yu Lee ${ }^{1}$, Alex Mok ${ }^{1}$, and Jacqueline Pui Wah Chung² \\ ${ }^{1}$ The Chinese University of Hong Kong Faculty of Medicine \\ ${ }^{2}$ The Chinese University of Hong Kong
}

July 6,2020

\begin{abstract}
The novel coronavirus SARS-CoV-2 was declared a pandemic on March 11, 2020. It utilizes angiotensin-converting enzyme 2 (ACE2) receptor in renin-angiotensin system (RAS) for viral entry. ACE2 is identified in female and male reproductive systems and reports of multi-organ involvement has led to uncertainty regarding its effects on reproductive systems and fertility. We review existing literature regarding function of ACE2 and RAS in reproductive systems to postulate the implications SARSCoV-2 may have on fertility and assisted reproductive technology (ART) outcomes. ART guidelines from different fertility societies are provided for management of ART patients and for ART laboratory regulations.
\end{abstract}

\section{Introduction}

COVID-19 is a serious respiratory disease caused by the SARS-CoV-2 virus. It was first identified in Wuhan, China, before being declared a pandemic on $11^{\text {th }}$ March 2020 by WHO. ${ }^{1}$ The global cases of COVID-19 have since increased exponentially, exceeding $9,600,000$ cases at the time of writing $\left(27^{\text {th }}\right.$ June, 2020). ${ }^{2}$

Common presentation include fever, cough, dyspnea, sputum, myalgias and bilateral infiltrates on chest Xray. $^{3}$ If severe, complications may develop, including acute respiratory distress syndrome, respiratory failure, thromboembolic events, multi-organ involvement and death. ${ }^{3,4}$

Main transmission routes are postulated to be via respiratory droplets, stool, blood, and ocular secretions. ${ }^{5-7}$ Incubation period is commonly $4-5$ days after exposure, but may be as long as 14 days. ${ }^{8}$ Common diagnostic tests include nucleic acid amplification test, serology testing and rapid antigen testing. ${ }^{9-11}$

Relationship between SARS-CoV-2, ACE2 and the Renin Angiotensin System (RAS)

SARS-CoV-2 enters the body via binding to angiotensin-converting enzyme 2 receptor (ACE2) expressed on target host cells. ${ }^{4}$ The spike protein of SARS-CoV-2 utilizes this receptor, similar to SARS-CoV-1, for cell fusion, endocytosis and cellular infection., ${ }^{4}, 12$ Figure 1 illustrates the role of ACE2 in the RAS., ${ }^{4}, 13$

AngII and Ang-(1-7) have opposing effects. AngII has pro-inflammatory, pro-fibrotic, pro-apoptotic and tissue remodeling properties while Ang-(1-7) is anti-inflammatory and anti-fibrotic. ${ }^{13}$ In other words, ACE1 and ACE2 counteract each other, and their roles are essential in balancing RAS.

SARS-CoV-1 studies revealed SARS-CoV-1 causes reduced ACE2 activity and expression. 4, 14, 15 There is indirect evidence to increased circulating AngII in SARS-CoV-2 patients. ${ }^{4,}{ }^{14}, 15$ As both viruses achieve viral entry via ACE2, it is postulated SARS-CoV-2 also causes ACE2 downregulation, leading to AngII increase. $^{14-19}$ This potentially explains the inflammatory and fibrotic effects seen in COVID-19 lung injury. ${ }^{14,16}$ 
There are increasing reports of multi-organ involvement in COVID-19 with SARS-CoV-2 found in blood, stools, urine and saliva. ${ }^{7}, 12,13,20$ This suggests ACE2 in different organ systems may contribute to pathophysiology of COVID-19 dissemination, through viraemia. ${ }^{4,12,13}$ ACE2 is found abundantly in various organ systems, including the testes and female reproductive system. ${ }^{20}$ Therefore, it is speculated the reproductive systems may too be affected by SARS-CoV-2. ${ }^{21}$ We review the existing literature on COVID-19, local RAS and their functions in reproductive systems to postulate how COVID-19 may affect both female and male steroidogenesis, germ cells, and reproductive health. ${ }^{21,22}$

COVID-19 Influence on the Female Reproductive System

\section{Ovary and Follicular Development}

While ACE2 is ubiquitous in the female productive system, it is found mostly in the ovaries. ${ }^{21-24}$ All other components of RAS are also found, making ovaries potential targets for SARS-CoV-2 damage. ${ }^{21-24}$

AngII, found predominantly in granulosa cells, regulates follicular development, oocyte maturation and ovulation. ${ }^{21,}{ }^{22}$ It is also involved in sex hormone secretion, follicular atresia, ovarian and corpus luteum angiogenesis. ${ }^{21,} 23$ Ang-(1-7), present in theca-interstitial cells, is involved in steroidogenesis, oocyte meiosis resumption, as well as follicular development, atresia and enhancing ovulation. ${ }^{21,}{ }^{22}$ ACE2, Ang-(1-7) and Mas-receptor are found in all stages of follicular development and studies with rats demonstrated altered expressions by gonadotropin, implicating the pathway's potential role in fertility. ${ }^{21,}{ }^{22}$ Furthermore, Ang(1-7) levels in follicular fluid collected during ovarian stimulation for in vitro fertilization (IVF) are found to positively correlate with the proportion of mature oocytes. ${ }^{25}$ Combined with animal studies proving a causal relationship between Ang-(1-7) and oocyte maturation, this implies Ang-(1-7) being a possible human oocyte maturation factor. ${ }^{25}$

SARS-CoV-2 ACE2 downregulation may cause alterations in normal ovarian physiology such as follicular development and oocyte maturation, which may significantly impact oocyte quality and fertility. In addition, AngII is shown to increase oxidative stress with pro- inflammatory effects. ${ }^{22}$ This may be detrimental to reproductive ability. Further investigations ought to be done to demonstrate whether increase in Ang II/AT1R signaling in SARS-CoV-2-B will affect ovarian physiology and fertility.

\section{Uterus and Fallopian Tubes}

RAS is identified in the uterus, with most confining in epithelial and stromal cells of the endometrium. ${ }^{21,} 23,26$ Little research is done to analyze their function, but their expressions fluctuate during the cycle. ${ }^{23}$ ACE2, Ang-(1-7) and Mas receptor expression are higher in secretory than proliferative phase while AngII and AT1R are higher in proliferative than secretory phase. ${ }^{21,23,26}$ If ACE2 is increased during secretory phase, this raises concern whether uterus may be more susceptible to SARS-CoV-2 during this period, leading to potential endometrial damage.

Normal level of AngII expression is crucial in maintaining regular menstrual cycles and endometrial activities. ${ }^{21}$ AngII facilitates blood vessels and endometrial regeneration and initiates menstruation. ${ }^{21}$ Endometrial and myometrial activities including endometrial regeneration, proliferation, fibrosis and stromal proliferation are regulated by the intricate balance of AngII and Ang-(1-7) in the uterus, stimulated by AngII and inhibited by Ang-(1-7). ${ }^{21}$ SARS-CoV-2 infection in the uterus may severely disrupt such balance. Disruption of AngII levels is found to be related to dysfunctional uterine bleeding associated with hyperplastic endometria. ${ }^{21}$ Whether this has any correlation to altered blood flow and increased risk of miscarriage is unknown.

In the fallopian tube, AngII is found in the endothelium and stroma. ${ }^{23}$ AT1R and AT2R are found in the epithelium. ${ }^{21,23,26}$ AT1R expression also changes throughout the cycle, higher in proliferative and lower in secretory phase, which is in line to uterus AngII/AT1R expression fluctuation. ${ }^{26}$ The function of AngII remains unclear, one study reported it stimulates ciliary beat frequency in epithelial cells. ${ }^{21,23,} 26$

Placenta 
A recent study detected positive SARS-CoV-2 in placental and fetal membrane, even though the infants tested negative in the first 5 days of life. ${ }^{27}$ Despite possible contamination from maternal blood, vaginal secretion and amniotic fluid, ${ }^{27}$ the risk of actual COVID-19 infection of the placenta and amniotic sac cannot be ignored, raising concern for risk of vertical transmission.

Placental ACE2 expression is found to be higher than its expression in the lungs ${ }^{21}$ further substantiating the risk of placental SARS-CoV-2 infection. It was reported that low placental ACE2 and Ang-(1-7) is associated with intrauterine growth restriction (IUGR), which evidently is also an outcome seen in pregnant COVID-19 patients. $^{21,28}$ This signifies placental COVID-19 infection may bring upon severe implications on pregnancy outcomes.

Local RAS is identified in placenta and cell lines as early as 6 weeks of gestation, but its function remains ambiguous. ${ }^{23}$ Some studies reported possible RAS involvement in trophoblast invasion and angiogenesis, and suggested local RAS alteration may contribute to abnormal utero-placental perfusion, leading to preeclampsia. ${ }^{23}$

AngII is found in maternal decidua and pericytes of endometrial spiral arteries. AT1R is found in maternal decidua, cytotrophoblast, syncytiotrophoblast and fetal capillaries. ${ }^{23}$ Ang-(1-7) and ACE2 are localized in syncytiotrophoblast, cytotrophoblast, endothelium and vascular smooth muscle of primary and secondary villi. ${ }^{21,}{ }^{23}$ ACE2 is also localized in invading and intravascular trophoblast and in decidual cells of maternal stroma. ${ }^{21}$ In the umbilical cord, ACE2 is localized in smooth muscles and vascular endothelium. ${ }^{21}$ All these serve as potential SARS-CoV-2 entry points to infect the placenta.

In addition, RAS expression fluctuation are observed throughout pregnancy. ${ }^{23}$ While AT1R expression increase during gestation and peaks at the end, ACE2 peaks early in gestation. ${ }^{21,}{ }^{23}$ Whether this causes increased susceptibility to placental SARS-CoV-2 infection at early gestation is unknown. ACE2 expression also differs in location throughout pregnancy: appearing in primary, secondary decidual zones, luminal and glandular epithelium at early gestation, and in labyrinth placenta, epithelium of amniotic and yolk sac at late gestation. ${ }^{21}$

\section{Implications on Assisted Reproductive Technology (ART) outcome}

SARS-CoV-2 infection may potentially bring on detrimental effects to female reproductive ability. It is also unknown how long the abnormality will last. Therefore, if recovered COVID-19 patients were to undergo ART, whether oocyte quality, quantity and other parameters will be affected is unknown, as well as the duration of abnormality. Future research should be conducted in a timely manner to assess these parameters.

COVID-19 Influence on the Male Reproductive System

\section{ACE2 in the Male Reproductive System}

ACE2 are found predominantly in the spermatogonia, Leydig cells and Sertoli cells of the testis, rendering them potential SARS-CoV-2 targets. ${ }^{22,29-32}$ Ang-(1-7) and Mas receptor are located in Leydig, Sertoli cells and in seminiferous tubules. ${ }^{22,32}$

Infertile men with severely impaired spermatogenesis are associated with lower ACE2, Ang-(1-7) and Mas receptor levels compared to fertile men. ${ }^{22,}{ }^{33}$ Men with non-obstructive azoospermia is found to have absence of Ang-(1-7) and Mas receptor in seminiferous tubules. ${ }^{32}$ As Leydig cell is responsible for steroidogenesis and secretion, particularly testosterone, ACE2, Ang-(1-7) and Mas expression in Leydig cells strongly suggest potential roles in regulation of steroidogenesis and secretion, spermatogenesis, and hence its influence on male fertility. ${ }^{22}$, ${ }^{2}$ Therefore, ACE2 Downregulation in COVID-19 may impair spermatogenesis and male fertility. Nevertheless, ACE2 knockout mice demonstrated no reduction in fertility, suggesting the possibility of other rescue mechanisms that may compensate for ACE2 loss. ${ }^{22,} 32$

AngII in testis inhibits Leydig cells, testosterone production, and regulate epididymis anion and fluid secretion. ${ }^{34}$ Hence, AngII increase in COVID-19 may hypothetically affect these functions. 


\section{Positive SARS-CoV-2 in Semen}

A recent study revealed 6 cases of positive SARS-CoV-2 in semen samples, with 4 in acute phase of infection and 2 in the recovery phase. ${ }^{35}$ This raises concern to sexual transmission in acute and particularly recovery phase of infection. This may have negative implications on fertility, assisted reproduction, vertical transmission and fetal development. Abstinence and condoms should be used to reduce potential risk of sexual transmission until more evidence is available..$^{35}$

\section{Orchitis in Coronavirus Infection}

Studies reported scrotal discomfort in SARS-CoV-2 patients suggesting viral orchitis. ${ }^{32,} 36,37$ However, semen parameters (sperm count, viability etc.) were not analyzed so whether male fertility is affected is unknown. ${ }^{32,36}$ Despite scrotal discomfort, one study reported absence of SARS-CoV-2 in semen following recovery. ${ }^{32}$

Nevertheless, orchitis as a complication to coronavirus infections such as SARS-CoV-1 is widely accepted. ${ }^{38,39}$ Pathological studies revealed testicular atrophy, germ cell destruction with decreased spermatozoon and inflammatory cell infiltrates. ${ }^{31,32,38,39}$ Interestingly, SARS-CoV-1 was not identified in the testis. Instead, high IgG precipitation was detected in the seminiferous epithelium, suggesting it may be an immune-mediated response causing the testicular damage, rather than direct testicular infection. ${ }^{32,}{ }^{38,}{ }^{39}$ If SARS-CoV-2 follows this mechanism, the scrotal discomfort may be explained. ${ }^{32}$ Inflammatory cells may disrupt spermatogenesis, impede steroidogenesis and destroy cells in seminiferous tubules. ${ }^{29}$ Cytokine release may activate autoimmune responses and produce antibodies within the seminiferous tubules. ${ }^{29}$ Semen analysis and follow up of patients with scrotal discomfort/orchitis in COVID-19 infection should be conducted to evaluate their reproductive functions.

\section{Implication on ART outcome}

SARS-CoV-2 infection and viral-mediated immune response may disrupt steroidogenesis, spermatogenesis and destroy cells of the seminiferous tubules. ${ }^{29,} 32$ In combination with risk of sexual transmission, the consideration of deferring conception of recovered patients until more evidence is available should be taken seriously. Semen analysis should be done in COVID-19 patients to analyze their reproductive ability. Sperm donation/cryopreservation of recovered COVID-19 patients should be avoided, as many viruses remain viable when cryopreserved and remains infectious. [ART6]

\section{ART Recommendations for COVID-19 Patients and General Public during the COVID-19 Pandemic}

\section{COVID-19 infection and possible ART outcome}

Due to the lack of actual quantitative evidence, COVID-19 having serious implication on fertility cannot be ruled out. Furthermore, fever is common in SARS-CoV-2 infection. In females undergoing ovarian stimulation for IVF, fever negatively affects follicular development and ovarian estradiol production. ${ }^{40}$ In males, fever transiently impairs spermatogenesis and sperm parameters (count, motility and DNA integrity) for 50-70 days. ${ }^{32,}$ 41, 42 Therefore, ART patients, gamete donors and gestation carriers with acute/recovered SARS$\mathrm{CoV}-2$ infection should avoid participation in any fertility programs until more research is conducted. ${ }^{31}$

\section{Guidelines to ART procedures}

Infertility is a time-sensitive disease; the longer left untreated, the lower the chances to becoming biological parents. Previously, fertility societies recommended cessation of all reproductive care except urgent cases. ${ }^{43}$ But as countries around the world begin to successfully mitigate the spread of COVID-19, a new joint statement released on May $29^{\text {th }}, 2020$ by The American Society of Reproductive Medicine (ASRM), the European Society of Human Reproduction and Embryology (ESHRE), and the International Federation of Fertility Societies (IFFS), declared sanctions on gradual resumption of full reproductive care in areas where COVID-19 has been better controlled. ${ }^{43}$ The recognition of the importance of fertility care provides a sigh of relief for infertile patients whose reproductive time is running out. 
Risk assessment should take place in ART centres before restarting services. ${ }^{44}$ Staff should closely monitor the COVID-19 situation in their hometowns for updated government information and regulation changes. ${ }^{44}$ ESHRE triage questionnaire should be done in all patients and partners 2 weeks prior to starting ART. ${ }^{45}$ Specific protocols should be enforced regarding screening and management of ART patients whom are high risk of/suspected of/confirmed with COVID-19. ${ }^{45}$ Table 1 below provides such guidelines by different fertility societies. ${ }^{45-50}$ ESHRE guideline is used as a reference point, if same recommendations as ESHRE are listed in other societies guidelines, they are omitted from the table. Only extra information are added. Due to the ongoing and everchanging nature of this pandemic, there may be future changes to ART regulations. The most updated regulations should be followed.

There is an increased risk of lung and kidney complications if COVID-19 patients develop ovarian hyperstimulation syndrome (OHSS) during ovarian stimulation. ${ }^{51}$ An individualized approach should be adopted. Anti-Mullerian hormone and antral follicle count should be used to assess ovarian reserve and guide the dosage of gonadotrophins. Gonadotrophin-releasing hormone $(\mathrm{GnRH})$ antagonist protocol with $\mathrm{GnRH}$ agonist triggering oocyte maturation and elective cryopreservation of embryos are extremely effective in minimizing OHSS risk. ${ }^{50}$

Infection control guidelines in ART centres and laboratories

Table 2 below lists recommendation for infection control in ART centres and laboratories to help reduce risk of COVID-19 spreading during procedures. ${ }^{44,}$ 45, 50-54

As SARS-CoV-2 can be present in semen, strict protective protocols should be implemented in handling these specimens. ${ }^{55}$ Extreme care should be taken during sperm cryobanking, and samples should be stored in highly secured segregated cryovessels. ${ }^{56}$ If the operator becomes infected, cryopreserved semen samples that were dealt with by the operator should be tested using polymerase chain reaction (PCR) ${ }^{54}$

\section{Identification of "time-sensitive" patients for ART}

With gradual resumption of reproductive services, it is crucial to identify and prioritize patients who have low prognosis to ART success and whose fertility potential deteriorate rapidly. ${ }^{50,53}$ Stratifying patients using the Poseidon group, Poseidon group 2 and 4 (advanced maternal age with normal/reduced ovarian reserve) patients should be prioritized, followed by group 3 ( age $<35$ but with reduced ovarian reserve). ${ }^{53}$ In males undergoing medical treatment to improve sperm quality and quantity, their "fertility window" is short and transient. Sperm analysis and banking should be done as soon as possible to increase their prospects of biological parenthood.

Regarding fertility preservation, patients with cancer, inflammatory and autoimmune diseases should be given priority, as their treatments are gonadotoxic. ${ }^{50,53,54}$ Fertility preservation can only be done during the "remission window", which is achieved after temporary discontinuation of therapy for 3-4 months. ${ }^{53,54}$ If unfortunately, their remission window coincided with the pandemic, they would have to either give up this ART opportunity and start gonadotoxic drugs again, meaning reduced ART success in future attempts as they age, or go an extended period of time without drugs in hopes of resumption of fertility care, but bearing the risk of flare up of their medical conditions. ${ }^{54}$

\section{Considerations for the general public wishing to undergo IVF}

Due to lack of data and knowledge on this novel coronavirus, thorough discussion with patients is imperative to increase their understanding of all the risks involved, which also includes risk of exposure at ART clinic during treatment. Infertility patients are facing high amount of stress due to fear of ART failure on top of uncertainty about the pandemic. ${ }^{50}$ Clinical and psychological support should be provided to advocate for patient well-being and to reduce treatment drop-out. In addition, it is of utmost importance to counsel patients about available options, from postponing treatment to resuming. Balancing of risks should be done between deferring treatment in low ART prognosis patients and undergoing treatment and its risk on fertility and pregnancy. ${ }^{53}$ 
The unknown effects of COVID-19 on reproductive systems, fertility and pregnancy outcomes must be discussed before starting IVF. While there is no clear evidence supporting vertical transmission, it cannot be ruled out due to COVID-positive placental and fetal membranes and neonates being tested positive after birth. ${ }^{12,}$ 27, 50, 52, 57-59 Immunosuppression and hormonal fluctuation during pregnancy leave women more vulnerable to respiratory pathogens and severe pneumonia. ${ }^{52}$ Nevertheless, there is no evidence stating increased susceptibility of COVID-19 in pregnancy. ${ }^{44}$ Pregnant women with COVID-19 also do not have symptoms more severe than non-pregnant women. ${ }^{52,57,60}$

Although the exact pathogenesis of COVID-19 in pregnancy is unclear, pregnancy with COVID-19 is associated with more maternal and fetal complications. ${ }^{52}$ These adverse pregnancy outcomes include preterm birth (most common), fetal distress, IUGR, increase caesarian sections, miscarriages, fetal, neonatal and maternal deaths. $^{28,52,59,61}$ Available data are from women infected during the third trimester, hence the COVID-19 effects on first trimester is unknown. ${ }^{52,57,62}$

\section{Conclusion}

COVID-19 has affected every part of the world, and it is likely to stay in the coming year. The potential risk of SARS-CoV-2 infection in reproductive systems, its effect on reproductive parameters and fertility cannot be ignored and hence warrants further quantitative research.

Shared decisions should be made between doctors and patients regarding fertility care. Patient autonomy allows them to decide whether to resume/postpone treatment and it is the doctors' responsibility to counsel them on all the risks and benefits involved. Individualization of each patient's ART treatment is the key to safe practice during this ongoing pandemic. ${ }^{57}$

\section{Acknowledgements}

None.

Disclosure of Interests

None.

\section{Contribution to Authorship}

WYLee and AMok, reviewed the literature, planned and drafted the manuscript. JPW Chung critically revised and supervised the manuscript writing.

Details of Ethics Approval

Nonapplicable.

Funding

None.

References

Uncategorized References

1. Jin Y, Yang H, Ji W, Wu W, Chen S, Zhang W, et al. Virology, Epidemiology, Pathogenesis, and Control of COVID-19. Viruses. 2020;12(4).

2. WHO Coronavirus Disease (COVID-19) Dashboard: World Health Organization; 2020 [updated 8:18am CEST, 27 June 2020. Available from: https://covid19. who.int/?gclid=Cj0KCQjw3Nv3BRC8ARIsAPh8hgKAP6sxurDSPnwnpDmv-WuAL5iPHUfa5FtAymnopwxJY7sK3J-UG8aAuGmEALw_wcB.

3. Wang D, Hu B, Hu C, Zhu F, Liu X, Zhang J, et al. Clinical Characteristics of 138 Hospitalized Patients With 2019 Novel Coronavirus-Infected Pneumonia in Wuhan, China. JAMA. 2020;323(11):1061-9. 
4. Sriram K, Insel PA. A hypothesis for pathobiology and treatment of COVID-19: The centrality of ACE1/ACE2 imbalance. Br J Pharmacol. 2020.

5. Chen W, Lan Y, Yuan X, Deng X, Li Y, Cai X, et al. Detectable 2019-nCoV viral RNA in blood is a strong indicator for the further clinical severity. Emerg Microbes Infect. 2020;9(1):469-73.

6. Colavita F, Lapa D, Carletti F, Lalle E, Bordi L, Marsella P, et al. SARS-CoV-2 Isolation From Ocular Secretions of a Patient With COVID-19 in Italy With Prolonged Viral RNA Detection. Ann Intern Med. 2020 .

7. Wang W, Xu Y, Gao R, Lu R, Han K, Wu G, et al. Detection of SARS-CoV-2 in Different Types of Clinical Specimens. JAMA. 2020;323(18):1843-4.

8. Guan WJ, Ni ZY, Hu Y, Liang WH, Ou CQ, He JX, et al. Clinical Characteristics of Coronavirus Disease 2019 in China. N Engl J Med. 2020;382(18):1708-20.

9. Patel A, Jernigan DB. Initial Public Health Response and Interim Clinical Guidance for the 2019 Novel Coronavirus Outbreak - United States, December 31, 2019-February 4, 2020. MMWR Morb Mortal Wkly Rep. 2020;69(5):140-6.

10. Interim Guidelines for COVID-19 Antibody Testing. Centers for Disease Control and Prevention; 2020.

11. M.D. SMH, Dr. Jeffrey E. Shuren MD J. Coronavirus (COVID-19) Update: FDA Authorizes First Antigen Test to Help in the Rapid Detection of the Virus that Causes COVID19 in Patients: U.S. Food and Drug Administration; 2020 [updated May 09, 2020. Available from: https://www.fda.gov/news-events/press-announcements/coronavirus-covid-19-update-fda-authorizesfirst-antigen-test-help-rapid-detection-virus-causes.

12. Li Y, Zhou W, Yang L, You R. Physiological and pathological regulation of ACE2, the SARS-CoV-2 receptor. Pharmacol Res. 2020;157:104833.

13. Bourgonje AR, Abdulle AE, Timens W, Hillebrands J-L, Navis GJ, Gordijn SJ, et al. Angiotensinconverting enzyme 2 (ACE2), SARS-CoV-2 and the pathophysiology of coronavirus disease 2019 (COVID19). The Journal of Pathology. 2020;251(3):228-48.

14. Kuba K, Imai Y, Rao S, Gao H, Guo F, Guan B, et al. A crucial role of angiotensin converting enzyme 2 (ACE2) in SARS coronavirus-induced lung injury. Nature Medicine. 2005;11(8):875-9.

15. Zhang H, Penninger JM, Li Y, Zhong N, Slutsky AS. Angiotensin-converting enzyme 2 (ACE2) as a SARS-CoV-2 receptor: molecular mechanisms and potential therapeutic target. Intensive Care Medicine. 2020;46(4):586-90.

16. Verdecchia P, Cavallini C, Spanevello A, Angeli F. The pivotal link between ACE2 deficiency and SARSCoV-2 infection. Eur J Intern Med. 2020;76:14-20.

17. Brojakowska A, Narula J, Shimony R, Bander J. Clinical Implications of SARS-CoV-2 Interaction With Renin Angiotensin System: JACC Review Topic of the Week. J Am Coll Cardiol. 2020;75(24):3085-95.

18. Dalan R, Bornstein SR, El-Armouche A, Rodionov RN, Markov A, Wielockx B, et al. The ACE-2 in COVID-19: Foe or Friend? Horm Metab Res. 2020;52(5):257-63.

19. Silhol F, Sarlon G, Deharo J-C, Vaïsse B. Downregulation of ACE2 induces overstimulation of the reninangiotensin system in COVID-19: should we block the renin-angiotensin system? Hypertension Research. 2020 .

20. Fu J, Zhou B, Zhang L, Balaji KS, Wei C, Liu X, et al. Expressions and significances of the angiotensinconverting enzyme 2 gene, the receptor of SARS-CoV-2 for COVID-19. Mol Biol Rep. 2020;47(6):4383-92.

21. Jing Y, Run-Qian L, Hao-Ran W, Hao-Ran C, Ya-Bin L, Yang G, et al. Potential influence of COVID19/ACE2 on the female reproductive system. Molecular Human Reproduction. 2020. 
22. Pan P-P, Zhan Q-T, Le F, Zheng Y-M, Jin F. Angiotensin-converting enzymes play a dominant role in fertility. Int J Mol Sci. 2013;14(10):21071-86.

23. Herr D, Bekes I, Wulff C. Local Renin-Angiotensin system in the reproductive system. Front Endocrinol (Lausanne). 2013;4:150-.

24. Reis FM, Bouissou DR, Pereira VM, Camargos AF, dos Reis AM, Santos RA. Angiotensin-(1-7), its receptor Mas, and the angiotensin-converting enzyme type 2 are expressed in the human ovary. Fertil Steril. 2011;95(1):176-81.

25. Cavallo IK, Dela Cruz C, Oliveira ML, Del Puerto HL, Dias JA, Lobach VN, et al. Angiotensin-(1-7) in human follicular fluid correlates with oocyte maturation. Hum Reprod. 2017;32(6):1318-24.

26. Vinson GP, Saridogan E, Puddefoot JR, Djahanbakhch O. Tissue renin-angiotensin systems and reproduction. Hum Reprod. 1997;12(4):651-62.

27. Penfield CA, Brubaker SG, Limaye MA, Lighter J, Ratner AJ, Thomas KM, et al. Detection of SARSCOV-2 in Placental and Fetal Membrane Samples. Am J Obstet Gynecol MFM. 2020:100133.

28. Dashraath P, Wong JLJ, Lim MXK, Lim LM, Li S, Biswas A, et al. Coronavirus disease 2019 (COVID-19) pandemic and pregnancy. Am J Obstet Gynecol. 2020;222(6):521-31.

29. Paoli D, Pallotti F, Colangelo S, Basilico F, Mazzuti L, Turriziani O, et al. Study of SARS-CoV-2 in semen and urine samples of a volunteer with positive naso-pharyngeal swab. J Endocrinol Invest. 2020:1-4.

30. Wang Z, Xu X. scRNA-seq Profiling of Human Testes Reveals the Presence of the ACE2 Receptor, A Target for SARS-CoV-2 Infection in Spermatogonia, Leydig and Sertoli Cells. Cells. 2020;9(4).

31. Cardona Maya WD, Du Plessis SS, Velilla PA. SARS-CoV-2 and the testis: similarity with other viruses and routes of infection. Reprod Biomed Online. 2020;40(6):763-4.

32. Younis JS, Abassi Z, Skorecki K. Is there an impact of the COVID-19 pandemic on male fertility? The ACE2 connection. American Journal of Physiology-Endocrinology and Metabolism. 2020;318(6):E878-E80.

33. Reis AB, Araújo FC, Pereira VM, Dos Reis AM, Santos RA, Reis FM. Angiotensin (1-7) and its receptor Mas are expressed in the human testis: implications for male infertility. J Mol Histol. 2010;41(1):75-80.

34. Leung PS, Sernia C. The renin-angiotensin system and male reproduction: new functions for old hormones. J Mol Endocrinol. 2003;30(3):263-70.

35. Li D, Jin M, Bao P, Zhao W, Zhang S. Clinical Characteristics and Results of Semen Tests Among Men With Coronavirus Disease 2019. JAMA Network Open. 2020;3(5):e208292-e.

36. Eisenberg ML. Coronavirus disease 2019 and men's reproductive health. Fertility and sterility. 2020;113(6):1154-.

37. Kim J, Thomsen T, Sell N, Goldsmith AJ. Abdominal and testicular pain: An atypical presentation of COVID-19. Am J Emerg Med. 2020:S0735-6757(20)30194-7.

38. Segars J, Katler Q, McQueen DB, Kotlyar A, Glenn T, Knight Z, et al. Prior and novel coronaviruses, Coronavirus Disease 2019 (COVID-19), and human reproduction: what is known? Fertility and sterility. 2020;113(6):1140-9.

39. Xu J, Qi L, Chi X, Yang J, Wei X, Gong E, et al. Orchitis: a complication of severe acute respiratory syndrome (SARS). Biol Reprod. 2006;74(2):410-6.

40. Awwad J, Ghazeeri G, Toth T, Hannoun A, Abdallah MA, Farra C. Fever in women may interfere with follicular development during controlled ovarian stimulation. International Journal of Hyperthermia. $2012 ; 28(8): 742-6$. 
41. Evenson DP, Jost LK, Corzett M, Balhorn R. Characteristics of human sperm chromatin structure following an episode of influenza and high fever: a case study. J Androl. 2000;21(5):739-46.

42. Sergerie M, Mieusset R, Croute F, Daudin M, Bujan L. High risk of temporary alteration of semen parameters after recent acute febrile illness. Fertil Steril. 2007;88(4):970.e1-7.

43. COVID-19 and Human Reproduction Joint Statement: ASRM, ESHRE, IFFS: International Federation of Fertility Societies; 2020 [updated May 29, 2020. Available from: https://www.iffsreproduction.org/news/510203/COVID-19-and-Human-Reproduction-Joint-StatementASRM-ESHRE-IFFS.htm.

44. American Society for Reproductive Medicine Patient Management and Clinical Recommendations During the Coronavirus (COVID-19) Pandemic UPDATE \#3 (April 24, 2020 through May 11, 2020): American Society of Reproductive Medicine; 2020 [updated May 11, 2020. Available from: https://www.asrm.org/globalassets/asrm/asrm-content/news-and-publications/covid19/covidtaskforceupdate3.pdf.

45. ESHRE guidance on recommencing ART treatments [press release]. ESHRE News: European Society of Human Reproduction and Embryology 2020.

46. American Society for Reproductive Care Patient Management and Clinical Recommendations During The Coronavirus (COVID-19) Pandemic Update \#4 (May 11, 2020 through June 8, 2020): American Society for Reproductive Care; 2020 [Available from: https://www.asrm.org/globalassets/asrm/asrm-content/newsand-publications/covid-19/covidtaskforceupdate4.pdf.

47. The Association of Reproductive and Clinical Scientists (ARCS) and British Fertility

Society (BFS) U.K. best practice guidelines for reintroduction of routine fertility

treatments during the COVID-19 pandemic.: British Fertility Society

The Association of Reproductive and Clinical Scientists 2020 [Available from: https://www.britishfertilitysociety.org.uk/wp-content/uploads/2020/05/ARCS-BFS-COVID-19-guidelinev1.1-1.pdf.

48. Statement of the Covid-19 FSA Response Committee (19 March 2020): The Fertility Society of Australia; 2020 [Available from: https://www.fertilitysociety.com.au/wp-content/uploads/20200319-COVID-19Statement-FSA-Response-Committee.pdf.

49. Updated Statement of the FSA COVID-19 Response Committee

(24 March 2020): The Fertility Society of Australia; 2020 [Available from: https://www.fertilitysociety.com.au/home/fsa-statement-covid-19/.

50. Vaiarelli A, Bulletti C, Cimadomo D, Borini A, Alviggi C, Ajossa S, et al. COVID-19 and ART: the view of the Italian Society of Fertility and Sterility and Reproductive Medicine. Reprod Biomed Online. 2020;40(6):755-9.

51. La Marca A, Niederberger C, Pellicer A, Nelson SM. COVID-19: lessons from the Italian reproductive medical experience. Fertility and sterility. 2020;113(5):920-2.

52. Monteleone PA, Nakano M, Lazar V, Gomes AP, de HM, Bonetti TC. A review of initial data on pregnancy during the COVID-19 outbreak: implications for assisted reproductive treatments. JBRA Assist Reprod. 2020;24(2):219-25.

53. Alviggi C, Esteves SC, Orvieto R, Conforti A, La Marca A, Fischer R, et al. COVID-19 and assisted reproductive technology services: repercussions for patients and proposal for individualized clinical management. Reprod Biol Endocrinol. 2020;18(1):45. 
54. Esteves SC, Lombardo F, Garrido N, Alvarez J, Zini A, Colpi GM, et al. SARS-CoV-2 pandemic and repercussions for male infertility patients: A proposal for the individualized provision of andrological services. Andrology. 2020.

55. Kashi AH. COVID-19 and Semen: An Unanswered Area of Research. Urol J. 2020;17(3):328.

56. Yakass MB, Woodward B. COVID-19: should we continue to cryopreserve sperm during the pandemic? Reprod Biomed Online. 2020;40(6):905-.

57. Souza M, Nakagawa H, Taitson PF, Cordts EB, Antunes RA. Management of ART and COVID-19: Infertility in Times of Pandemic. What Now? JBRA Assist Reprod. 2020.

58. Alzamora MC, Paredes T, Caceres D, Webb CM, Valdez LM, La Rosa M. Severe COVID-19 during Pregnancy and Possible Vertical Transmission. Am J Perinatol. 2020.

59. Juan J, Gil MM, Rong Z, Zhang Y, Yang H, Poon LC. Effects of coronavirus disease 2019 (COVID-19) on maternal, perinatal and neonatal outcomes: a systematic review. Ultrasound in Obstetrics \& Gynecology.n/a(n/a).

60. Elshafeey F, Magdi R, Hindi N, Elshebiny M, Farrag N, Mahdy S, et al. A systematic scoping review of COVID-19 during pregnancy and childbirth. Int J Gynaecol Obstet. 2020;150(1):47-52.

61. Yang Z, Wang M, Zhu Z, Liu Y. Coronavirus disease 2019 (COVID-19) and pregnancy: a systematic review. J Matern Fetal Neonatal Med. 2020:1-4.

62. Rodriguez-Wallberg KA, Wikander I. A global recommendation for restrictive provision of fertility treatments during the COVID-19 pandemic. Acta Obstetricia et Gynecologica Scandinavica. 2020;99(5):569-70.

\begin{tabular}{|c|c|c|}
\hline & Already started cycles: & Planned cycles/pregnancy: \\
\hline $\begin{array}{l}\text { The European Society of } \\
\text { Human Reproduction and } \\
\text { Embryology }{ }^{45} \text { (last updated } \\
05 / 05 / 2020 \text { ) }\end{array}$ & $\begin{array}{l}\text { Resume usual protocols unless } \\
\text { changes occur between ovulation } \\
\text { trigger and oocyte retrieval. If } \\
\text { positive triage, test SARS-CoV-2 } \\
\text { IgM/IgG and/or reverse } \\
\text { transcription polymerase chain } \\
\text { reaction. Decide to continue/defer } \\
\text { based on result. If tests positive } \\
\text { before ovulation trigger/embryo } \\
\text { thawing, defer treatment. If } \\
\text { potentially positive patient must } \\
\text { continue treatment (oncological } \\
\text { patient or high risk OHSS), the } \\
\text { following should be implemented: } \\
\text { Filtering Facepiece (FFP) } 2 \text { or } 3 \\
\text { masks Gowning COVID-19 } \\
\text { specific disinfection of all areas } \\
\text { after procedure If patient/partner } \\
\text { symptomatic after oocyte } \\
\text { retrieval/suspected of/positive } \\
\text { during embryo culture, adopt } \\
\text { freeze-all policy. Embryo transfer } \\
\text { (ET) only for low } \\
\text { risks/asymptomatic cases. }\end{array}$ & $\begin{array}{l}\text { All patients can choose to } \\
\text { continue/postpone ART. }\end{array}$ \\
\hline
\end{tabular}




\begin{tabular}{|c|c|c|}
\hline & Already started cycles: & Planned cycles/pregnancy: \\
\hline $\begin{array}{l}\text { Additional } \\
\text { recommendations not } \\
\text { mentioned in ESHRE in } \\
\text { other fertility societies: } \\
\text { The American Society of } \\
\text { Reproductive Medicine }{ }^{46} \\
(11 / 05 / 2020)\end{array}$ & $\begin{array}{l}\text { Additional } \\
\text { recommendations not } \\
\text { mentioned in ESHRE in } \\
\text { other fertility societies: } \\
\text { For donor/gestational carrier: } \\
\text { defer oocyte retrieval and ET if } \\
\text { positive/symptomatic during } \\
\text { stimulation/before ET. }\end{array}$ & $\begin{array}{l}\text { Additional } \\
\text { recommendations not } \\
\text { mentioned in ESHRE in } \\
\text { other fertility societies: }\end{array}$ \\
\hline $\begin{array}{l}\text { The Association of } \\
\text { Reproductive and Clinical } \\
\text { Scientists and British } \\
\text { Fertility Society } \\
(06 / 05 / 2020)\end{array}$ & $\begin{array}{l}\text { Patient/donor suspected } \\
\text { of/positive after ovulatory } \\
\text { trigger, risk assessment should } \\
\text { be done to assess whether to } \\
\text { continue/postpone oocyte } \\
\text { retrieval }\end{array}$ & $\begin{array}{l}\text { Do screening questionnaire }+/- \\
\text { antigen testing. Positive } \\
\text { patients/donors defer ART } \\
\text { until completely recovered and } \\
\text { not infectious. }\end{array}$ \\
\hline $\begin{array}{l}\text { Fertility Society of } \\
\text { Australia }^{48,49}(24 / 03 / 2020)\end{array}$ & $\begin{array}{l}\text { High risk patients should consider } \\
\text { cycle cancellation, oocyte and } \\
\text { embryo freezing and defer ET } \\
\text { until complete recovery. }\end{array}$ & $\begin{array}{l}\text { Discuss appropriateness of } \\
\text { postponing treatment. Any } \\
\text { medical conditions warranting } \\
\text { treatment be continued? }\end{array}$ \\
\hline $\begin{array}{l}\text { The Italian Society of } \\
\text { Fertility and Sterility and } \\
\text { Reproductive Medicine }\end{array}$ & & $\begin{array}{l}\text { Defer in high risk patients with } \\
\text { pre-existing medical history such } \\
\text { as renal, liver, heart diseases, } \\
\text { diabetes mellitus, hypertension, } \\
\text { and immunosuppressive } \\
\text { conditions. Prioritize urgent } \\
\text { patients to start ART. Defer } \\
\text { treatment for young patients } \\
\text { undergoing ovulation induction } \\
\text { for timed sexual intercourse and } \\
\text { intrauterine insemination. }\end{array}$ \\
\hline
\end{tabular}

Table 1: Guidelines for high risk/COVID-19 positive ART patients

\section{ART Centres}

Telehealth (phone/video call): symptom screening/questionnaire, travel and close contact history and for all medical consul

Table 2: Infection control recommendation for ART centres and laboratories

\section{Hosted file}

Figure.docx available at https://authorea.com/users/337631/articles/463266-potential-covid19-effects-on-reproductive-systems-and-fertility-art-guidelines-and-considerations-a-

review 